DOI: 10.12731/wsd-2017-2-158-167

УДК 613.95

\title{
ИСПОЛЬЗОВАНИЕ КОМПЬЮТЕРНЫХ ТЕХНОЛОГИЙ ПРИ ПРОВЕДЕНИИ ДИСПАНСЕРИЗАЦИИ ДЕТСКОГО НАСЕЛЕНИЯ РЕСПУБЛИКИ ТЫВА
}

\section{Грицинская В.Л., Москаленко О.Л.}

Цель. Оптимизаџия диспансеризаџии детского населения Тывы с использованием автоматизированной стандартизированной оценки параметров.

Материалы и методы. Исследование проведено в два этапа. На первом этапе проведено обследование 7416 детей и подростков коренного и пришлого населения Республики Тыва в возрасте от 3 до 18 лет. Обследование включало соматометрию, кистевую динамометрию, измерение артериального давления и подсчет числа сердечных сокращений. На основании этих данных разработаны региональные нормативы антропометрических показателей и создана программа для ЭВМ «АИСТ, позволяющая оченивать уровень физического развития, физической подготовленности и функииональные резервы организма детей. На втором этапе проведена оиенка данных, полученных при медицинских осмотрах 1879 школьников, с помощью разработанной программы.

Результаты. Установлено, что значительная часть обследованных школьников имеет дисгармоничные варианты физического развития и высокую интенсивность ростовых прочессов, что позволяет отнести их в группу риска вероятного снижения резистентности и работоспособности. Наиболее вероятными и управляемыми факторами, способствующими возникновению отклонений в росте и развитии детей, является нерациональное, несбалансированное питание и нарушение пищевого поведения, низкая двигательная активность.

Заключение. Внедрение программы в практику здравоохранения позволило оптимизировать проведение диспансерных осмотров и создать компьютерные базы данных обследования детского населения.

Ключевые слова: дети; физическое развитие; стандарты; методы оченки. 


\section{USE OF COMPUTER TECHNOLOGIES WHEN CARRYING OUT MEDICAL EXAMINATIONS OF THE CHILDREN'S POPULATION OF THE REPUBLIC OF TYVA}

\section{Gritsinskaya V.L., Moskalenko O.L.}

The purpose of the study. Optimization of the medical examination of the children's population of Tyva with the use of automated standardized parameter estimation.

Materials and methods. The study was carried out in two stages. At the first stage, 7,416 children and adolescents of the indigenous and newborn population of the Republic of Tuva aged 3 to 18 were examined. The examination included somatometry, carpal dynamometry, blood pressure measurement and heart rate counting. Based on these data, regional standards for anthropometric indicators have been developed and a computer program "AIST has been created that allows to assess the level of physical development, physical readiness and functional reserves of the children's organism. At the second stage, the data obtained during medical examinations of 1879 schoolchildren was assessed using the developed program.

Results. It was established that the considerable part of the examined children has disharmonious options of physical development and high intensity of growth processes that allows carrying them into a group of risk of probable decrease of resistance and working capacity. The most probable and operated factors promoting emergence of deviations in physical development of children is irrational, unbalanced food, violation of food behavior and low physical activity.

Conclusion. Introduction of the program in practice of health care allowed to optimize carrying out dispensary surveys and to create computer databases of inspection of the children's population.

Keywords: children; physical development; standards; assessment methods.

В национальных стратегических документах РФ ведущим направлением развития здравоохранения в ближайшие годы является профилактическое [1, с. 107-111; 2, с. 3-9]. Диспансеризация детского населения получила новое развитие с началом действия Приказа Минздрава России от 21.12.2012 №1346н «О порядке прохождения несовершеннолетними 
медицинских осмотров, в том числе при поступлении в образовательные учреждения и в период обучения в них». При проведении профилактических, предварительных и периодических медицинских осмотров несовершеннолетних особое внимание уделяется оценке физического развития и функциональных резервов детей.

В ряде исследованиях показано, что для характеристики физического развития (ФР) коллективов, различающихся по этническому признаку, климатическим и социально-экономическим условиям проживания, наиболее информативными являются методики, использующие региональные нормативы [3, с. 14-16; 4, с. 90-93; 5, с. 8-11; 6, с. 10-34]. Актуально также для индивидуализации оценки роста и развития определение морфофенотипа (соматотипа), как внешней, наиболее доступной к исследованию конституциональной характеристики человека $[7$, с. 9-14; 8, с. 6-8; 9, с. 442-449].

В сложной демографической ситуации особого внимания заслуживает сохранение здоровья детского населения коренных и малочисленных народностей Севера и Сибири. Республика Тыва - территория компактного проживания коренного населения Сибири - тувинцев; доля пришлого населения не превышает 5-6\%. Условия проживания в республике характеризуются комплексом экстремальных климатогеографических факторов и неблагоприятной геохимической структурой окружающей среды. Низкая плотность населения, отдаленность большинства населенных пунктов от медицинских центров затрудняет проведение диспансеризации детского населения. В данной ситуации актуальна разработка унифицированных компьютерных программ оценки морфофункциональных показателей детей, что явилось целью нашей работы.

\section{Материалы и методы}

На первом этапе работы проведено обследование 7416 детей и подростков коренного и пришлого населения Республики Тыва в возрасте от 3 до 18 лет. Обследование включало соматометрию (длина и масса тела, окружность грудной клетки), кистевую динамометрию, измерение артериального давления и подсчет числа сердечных сокращений. На основании полученных данных разработаны с учетом этнической принадлежности региональные нормативы (центильные таблицы) основных соматометрических и функциональных показателей, которые положены в основу компьютерной программы (Свидетельство о государственной регистрации программы для ЭВМ № 2013619795 от 16.10.2013 г.). 
Компьютерная программа «АИСТ» (Автоматизированное Индивидуальное СоматоТипирование) позволяет определять: уровень и гармоничность ФР, темп ростовых процессов (соматотип), направленность ростовых процессов (тип телосложения), уровень физической подготовленности, исходный уровень вегетативного обеспечения, функциональные резервы сердечно-сосудистой системы. Для установки программы необходим персональный компьютер с базовыми программами Windows XP или Windows Vista, или Windows 7. Обработка данных проводится в течение нескольких секунд. Предусмотрена распечатка результатов обследования ребенка. Параллельно возможно формирование базы данных с сохранением полученных результатов обследования.

Уровень ФР определяется в зависимости от соответствия длины тела ребенка возрастным нормативам, с выделением следующих вариантов: среднее (СФР, 25-75 центили), ниже среднего (НСФР, 25-10 ц.), низкое (НФР, ниже10 ц.), выше среднего (ВСФР, 75-90 ц.), высокое (ВФР, выше 90 ц.). Гармоничность ФР оценивается с помощью индекса Кет$л_{2}$, значение которого определяется путем деления массы тела (кг) на квадрат длины тела $\left(\mathrm{M}^{2}\right)$. В зависимости от соответствия значения индекса нормативам центильной шкалы (В.В. Юрьев, Н.Н. Воронович, О.Ю. Паршуткина, 2004 г.) выделены следующие варианты ФР: гармоничное (ГФР; 25-75 центили), дисгармоничное за счет дефицита массы тела (ДМТ; ниже 25 ц.), дисгармоничное за счет избыточной массы тела (ИМТ; выше 75 ц.). Определение соматотипа проводится по методу Р.Н. Дорохова и И.И. Бахрах в модификации И.М. Воронцова (1986 г.). В зависимости от суммы номеров «коридоров» центильной шкалы для длины, массы тела, окружности грудной клетки, выделены следующие соматические типы: микросомный (3-10), мезосомный (11-15), макросомный (16-21). Для характеристики типа телосложения используется индекс «стении» Вервека-Воронцова (1986 г.); значением индекса является частное от деления длины тела (см) на сумму окружности грудной клетки (см) и удвоенной массы тела (кг). Выделены следующие типы телосложения: долихоморфия (преобладание линейного роста), мезоморфия (гармоничное соотношение процессов линейного и объемного роста), брахиморфия (преобладание роста в ширину). Оценка уровня артериального давления, частоты сердечных сокращений и показателей кистевой динамометрии проводится с учетом региональных нормативов. Исходный тонус вегетативной нервной системы определяется с помощью вегетативного индекса Кердо (ВИК) по формуле: [1 - (диа- 
столическое АД / число сердечных сокращений)] х 100. Положительное значение ВИК свидетельствует о преобладании симпатических влияний (симпатикотония), отрицательное - о преобладании парасимпатических влияний (ваготония); при равновесии состояния вегетативной нервной системы ВИК $=0$ (эйтония). За норму принимаются значения ВИК в пределах от «-» 10 до «+» 10\%. Оценка функциональных резервов сердечно-сосудистой системы проводится при помощи индекса Руфье, определяемого как одна сотая произведения числа сердечных сокращений и систолического АД. Выделены уровни резервов: высокие (менее 80 ), средние (от 80 до 90) и низкие (91 и выше).

На втором этапе проведена оценка данных, полученных при медицинских осмотрах школьников, с помощью программы «АИСТ». Обследовано 1879 учащихся образовательных школ (1615 тувинцев и 264 представителя пришлого населения) в г. Кызыле - столице Тывы. В соответствии с возрастной периодизацией обследованные поделены на группы: младшие (7-11 лет) и старшие школьники (12-18 лет). Статистическая обработка выполнена с помощью прикладных программ «STATISTICA v. 7.0 (C) STATSOFT, USA» с использованием критерия $\chi^{2}$ в модификации Пирсона. Результаты исследования представлены в виде Р[ДИ]\%, где Р процентная доля, ДИ - 95\% доверительный интервал для доли. Результаты считали статистически значимыми при р $<0,05$.

\section{Результаты}

У обследованных школьников чаще определялось среднее ФР. У тувинцев число таких учеников в старшей возрастной группе больше $(48,8 \%[47,3-50,3])$, чем среди младших школьников $(45,3 \%$ [43,5-47,1]). Младших школьников-тувинцев со СФР было меньше, чем сверстников пришлого населения $(54,3 \%$ [48,8-59,9]; $\mathrm{p}=0,03)$. Самое низкое число школьников со СФР было среди старшеклассников пришлого населения $(39,6 \%$ [35,4-43,8]), причем разница показателей статистически значима как в сравнении с учениками младших классов $(\mathrm{p}=0,02)$, так и по отношению к сверстникам коренного населения $(\mathrm{p}=0,007)$. Школьников с ФР ниже среднего среди тувинцев было $26 \%[24,4-27,6]$ в обеих возрастных группах. В группе младших школьников пришлого населения детей с НСФР меньше (17,3\% [13,1-21,5]), чем у старшеклассников своей этнической группы $(30,0 \%[26,1-33,8] ; \mathrm{p}=0,002)$ и ровесников-тувинцев $(\mathrm{p}=0,016)$. Число школьников, имеющих длину тела выше возрастных нормативов, во всех группах существенно не отличалось. 
Школьников с гармоничным соотношением массы и длины тела больше среди тувинцев $(53,0 \%$ [51,1-54,9]), чем среди представителей пришлого населения (в младшей возрастной группе - 40,7\% [35,3-46,1]; $\mathrm{p}=0,005 ;$ у старшеклассников - 45,5\% [41,2-49,8]; $\mathrm{p}=0,03)$. У старшеклассников-тувинцев одинаково часто отмечаются дисгармоничные варианты, обусловленные как дефицитом, так и избытком массы тела. В группе младших школьников коренного населения превалируют отклонения, обусловленные ИМТ $(27,5 \%$ [25,8-29,2]). У младших школьников пришлого населения также превалируют дисгармоничные варианты, обусловленные ИМТ (40,7\% [35,3-46,1]), но чаще, чем у сверстников-тувинцев $(\mathrm{p}<0,001)$ и старших школьников своей этнической группы $(\mathrm{p}=0,007)$. У старшеклассников пришлого населения чаще отмечается дисгармония ФР, обусловленная ДМТ (31,4\% [27,4-35,4]), причем разница показателей статистически значима как в сравнении с учениками младших классов в своей этнической группе ( $\mathrm{p}=0,002)$, так и со сверстниками-тувинцами $(\mathrm{p}=0,006)$.

У большинства обследованных школьников определялся мезосоматотип, не выявлено различий в распределении в зависимости этнической принадлежности $(57,8-59,0 \%)$. Среди тувинцев больше школьников с микросоматотипом $(27,0 \%[25,9-28,1])$, чем у школьников пришлого населения $(21,4 \%[18,7-24,1] ; \mathrm{p}=0,02)$. Школьников с макросоматотипом больше среди детей пришлого населения $(\mathrm{p}=0,05)$.

Гармоничное соотношение процессов линейного и объемного роста отмечалось у большинства обследованных. Школьников с мезоморфным типом телосложения больше среди младших школьников, чем среди старшеклассников; как среди тувинцев $(88,4 \%$ [87,1-89,7] и 82,0\% [80,8$83,2] ; \mathrm{p}<0,001)$ так и учащихся пришлого населения $(91,4 \%[88,4-94,4]$ и 78,7\% [75,2-82,2]; p< 0,001). Долихоморфный тип телосложения чаще встречается у младших школьников коренного населения $(8,6 \%[7,5-9,7])$, чем у старшеклассников-тувинцев $(1,9 \%[1,5-2,3] ; \mathrm{p}<0,001)$, несмотря на то, что в подростковом возрасте происходит пубертатный скачок роста; у школьников пришлого населения не выявлено различий от возраста. Брахиморфный тип телосложения чаще регистрируется у старшеклассников $(16,1 \%[15,0-17,2]$ у тувинцев и $15,8 \%[12,6-19,0])$ у школьников пришлого населения), чем у учащихся младших классов $(3,0 \%[2,3-3,7]$ и $3,7 \%[1,7-5,7]$ соответственно; $\mathrm{p}<0,001)$.

Вегетативный тонус, отражающий интегральное состояние соматических функций, выступает как один из основных признаков успеш- 
ной адаптации школьников. У большинства детей выявлено увеличение влияния симпато-адреналовой системы (у младших школьников - 81,4\% $[79,9-82,9]$ и у старшеклассников - 58,9\% [56,6-61,2]; $\mathrm{p}<0,001)$, что может свидетельствовать о напряжении механизмов адаптации и снижении функциональных резервов учащихся. Увеличение влияния парасимпатического отдела вегетативной нервной системы отмечается с возрастом: у старшеклассников в 32,6\% [30,5-34,7] случаев зарегистрирована эйтония, ваготония - у 8,5\% [7,2-9,8] школьников; в младшей возрастной группе таких детей $16,8 \%$ [14,6-19,0] и 1,8\% [1,1-2,5] соответственно ( $<<0,001)$. Высокие резервы функционального состояния ССС в младшей возрастной группе $34,0 \%$ [36,5-31,5] регистрировались чаще, чем у старшеклассников $24,2 \%[22,1-26,3](\mathrm{p}=0,006)$. Соответственно у старшеклассников чаще выявлялись низкие функциональные резервы ССС 52,0\% [49,8-54,2], чем у младших школьников $38,5 \%$ [35,9-41,1]; число детей со средними функциональными резервами ССС в обеих возрастных группах существенно не различалось. Отмечено, что у $35,8 \%$ [33,3-38,3] детей в младшей возрастной группе и 25,3\% [23,1-27,5] старшеклассников показатели кистевой динамометрии ниже возрастных нормативов.

\section{Заключение}

Таким образом, разработанная нами компьютерная программа «АИСТ» позволяет проводить дифференцированную оценку физического развития и функциональных резервов организма детей с учетом этнической и индивидуально-типологической принадлежности ребенка. Применение программы при проведении медицинских осмотров школьников позволило выявить возрастные и этнические особенности роста, развития и адаптационных возможностей учащихся. Дисгармоничные варианты физического развития чаще выявлялись у школьников пришлого населения. Для младших школьников, вне зависимости от этнической принадлежности, в большей степени характерна дисгармония за счет избыточной массы тела; у старшеклассников - за счет дефицита массы тела. Наиболее вероятными и управляемыми факторами, способствующими возникновению отклонений в физическом развитии детей, является нерациональное, несбалансированное питание и нарушение пищевого поведения, низкая двигательная активность. У значительной части школьников вне зависимости от этнической принадлежности отмечалось напряжение механизмов адаптации и снижении функциональных резервов организма. 
Применение программы «АИСТ» в рамках проведения диспансеризации детского населения Республики Тыва позволяет унифицировать оценку морфофункциональных показателей детей и сократить время обработки результатов.

\section{Сиисок литературы}

1. Кучма В.Р., Милушкина О.Ю., Бокарева Н.А., Скоблина Н.А. Современные направления профилактической работы в образовательных организациях. Гигиена и санитария. 2014; 93 (6): 107-111.

2. Яковлева Т.В., Баранов А.А., Иванова А.А., Альбицкий В.Ю. Организационные принципы и технологии профилактики XXI века. Проблемы социальной гигиены, здравоохранения и истории медицины. 2014; 22 (6): 3-9.

3. Ануфриева Е.В. Новые подходы к диспансеризации детей подросткового возраста. Российская академия мед. наук. Бюллетень Национального научно-исследовательского института общественного здоровья. 2012; 4: 14-16.

4. Ермолаева С.В. Оценка физического развития и адаптивных возможностей организма школьников Ульяновской области. Гигиена и санитария. 2014; 93 (4): 90-93.

5. Грицинская ВЛ. Характеристика физического развития питания школьников городского и сельского населения Красноярского края. Вопросы детской диетологии. 2012; 10(5): 8-11.

6. Антропометрические особенности и компонентный состав массы тела у мужчин мигрантов крайнего Севера с артериальной гипертонией. Яскевич Р.А., Москаленко О.Л. В мире научных открытий. 2016. № 10 (82). С. 10-34.

7. Никитюк Д.Б., Миннибаев Т.Ш., Клочкова С.В., Алексеева Н.Т., Тимошенко К.Т. Роль антропометрического метода в оценке физического развития детей и подростков в норме и патологии. Журнал анатомии и гистопатологии. 2014; 3 (11): 9-14.

8. Грицинская В.Л., Сенди С.С. Особенности физического развития и питания школьников Республики Тыва. Вопросы детской диетологии. 2012; 10 (4): 6-8.

9. Характеристика свойств темперамента у юношей-студентов разных соматотипов г. Железногорска. Москаленко О.Л. В мире научных открытий. 2015. № 8.1 (68). C. 442-449.

\section{References}

1. Kuchma V.R., Milushkina O.Yu., Bokareva N.A., Skoblina N.A. Sovremennye napravleniya profilakticheskoy raboty v obrazovatel'nykh organizatsiyakh 
[Modern trends of preventive work in educational institutions]. Gigiena $i$ sanitariya [Hygiene and sanitation]. 2014; 93 (6): 107-111 (in Russian).

2. Yakovleva T.V., Baranov A.A., Ivanova A.A., Albitskiy V.Yu. Organizatsionnye printsipy i tekhnologii profilaktiki XXI veka [The organizational principles and technologies of prevention of the XXI century]. Problemyi sotsialnoy gigienyi, zdravoohraneniya i istorii meditsinyi. 2014; 22 (6): 3-9 (in Russian).

3. Anufrieva Ye.V. Novye podkhody k dispanserizatsii detey podrostkovogo vozrasta [New approaches to the mass health examination of teen-age children]. Rossiyskaya akademiya med. nauk. Byulleten' Natsional'nogo nauchno-issledovatel'skogo instituta obshchestvennogo zdorov'ya. 2012; 4: 14-16 (in Russian).

4. Yermolaeva S.V. Otsenka fizicheskogo razvitiya i adaptivnykh vozmozhnostey organizma shkol'nikov Ul'yanovskoy oblasti [Evaluation of the physical development and adaptation capacities of the body of schoolchildren in the Ulyanovsk Region]. Gigiena i sanitariya [Hygiene and sanitation]. 2014; 93 (4): 90-93. (in Russian).

5. Gritsinskaya V.L. Kharakteristika fizicheskogo razvitiya pitaniya shkol'nikov gorodskogo i sel'skogo naseleniya Krasnoyarskogo kraya [A characteristic of physical development and nutrition of schoolchildren of the urban and rural population of the Krasnoyarsk krai]. Voprosy detskoy dietologii [Questions of children's dietology]. 2012; 10(5): 8-11. (in Russian).

6. Yaskevich R.A., Moskalenko O.L. Antropometricheskie osobennosti i komponentnyy sostav massy tela u muzhchin migrantov kraynego Severa s arterial'noy gipertoniey [Anthropometric features and component composition of body weight in men of migrants of the extreme North with arterial hypertension]. Vmire nauchnykh otkrytiy [In the world of scientific discoveries]. 2016. № 10 (82), pp. 10-34.

7. Nikityuk D.B., Minnibaev T.Sh., Klochkova S.V., Alekseeva N.T., Timoshenko K.T. Rol' antropometricheskogo metoda $\mathrm{v}$ otsenke fizicheskogo razvitiya detey i podrostkov v norme i patologii [The role of the anthropometric method in the evaluation of physical development of children and adolescents]. Zhurnal anatomii i gistopatologii [Journal of Anatomy and Histopathology]. 2014; 3 (11): 9-14 (in Russian).

8. Gritsinskaya V.L., Sendi S.S. Osobennosti fizicheskogo razvitiya i pitaniya shkol'nikov Respubliki Tyva [Specificities of physical development and nutrition of schoolchildren of the Republic of Tuva]. Voprosy detskoy dietologii [Questions of children's dietology]. 2012; 10 (4): 6-8 (in Russian).

9. Moskalenko O.L. Kharakteristika svoystv temperamenta u yunoshey-studentov raznykh somatotipov g. Zheleznogorska [Characteristics of the temperament properties of young students-students of different somatotypes in Zhelezno- 
gorsk]. V mire nauchnykh otkrytiy [In the world of scientific discoveries]. 2015. № 8.1 (68), pp. 442-449.

\section{ДАННЫЕ ОБ АВТОРАХ}

Грицинская Вера Людвиговна, доктор медицинских наук, профессор кафедры детских болезней, ведущий научный сотрудник научно-исследовательской лаборатории детской эндокринологии ФГБУ «Северо-Западный федеральный медицинский исследовательский иенттр им. В.А. Алмазова» Минздрава России ул. Аккуратова, 2, г. Санкт-Петербург, 197341, Российская Федерациия

tryfive@mail.ru

Москаленко Ольга Леонидовна, старший научный сотрудник, кандидат биологических наук Федеральное государственное бюджетное научное учреждение «Научно-исследовательский институт медицинских проблем Севера» ул. Партизана Железняка, 32, г. Красноярск, 660022, Российская Федераиия gre-ll@mail.ru

\section{DATA ABOUT THE AUTHORS}

Gritsinskaya Vera Lyudvigovna, Doctor of Medical Sciences, Professor of Department of Children's Diseases, Leading Researcher of Research Laboratory of Children's Endocrinology

V.A. Almazov Federal North-West medical research centre» of the ministry of health of the Russian Federation

2 Akkuratova Str., St. Petersburg, 197341, Russian Federation tryfive@mail.ru

Moskalenko Olga Leonidovna, Senior Researcher, Candidate of Biological Sciences

Federal State Budgetary Scientific Institution «Scientific Research Institute of medical problems of the North»

3g, Partizan Zheleznyak Str., Krasnoyarsk, 660022, Russian Federation gre-ll@mail.ru

SPIN-code: 9730-6265

ORCID: 0000-0003-4268-6568 